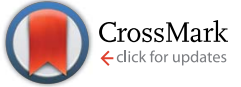

Cite this: RSC Adv., 2017, 7, 14694

Received 30th November 2016 Accepted 24th February 2017

DOI: 10.1039/c6ra27543e

rsc.li/rsc-advances

\section{Ultra-thin ZnO film as an electron transport layer for realizing the high efficiency of organic solar cells $\uparrow$}

\author{
Dan Chi, ${ }^{\text {a }}$ Shihua Huang, ${ }^{\text {a }}$ Shizhong Yue, ${ }^{\mathrm{b}}$ Kong Liu, ${ }^{\mathrm{b}}$ Shudi Lu, ${ }^{\mathrm{b}}$ Zhijie Wang, $^{\text {*b }}$ \\ Shengchun $\mathrm{Qu}^{* \mathrm{~b}}$ and Zhanguo Wang ${ }^{\mathrm{b}}$
}

\begin{abstract}
To overcome the limits of low charge transport efficiency and high absorption in the UV region of conventional thick $\mathrm{ZnO}$ layers in organic solar cells, herein we introduce an ultra-thin $\mathrm{ZnO}$ film (4 nm) into PBDTTT-CF:PC $70 \mathrm{BM}$ bulk heterojunction organic solar cells, as the electron transport layer, and realize a power conversion efficiency of $7.51 \%$, which is dramatically higher than that of a device using general $\mathrm{ZnO}$ film (28.1 nm). Various techniques from both steady-state and ultra-fast views reveal that the devices with an ultra-thin ZnO film (less than $10 \mathrm{~nm}$ ) show a higher built-in potential compared to the device with a $28.1 \mathrm{~nm} \mathrm{ZnO}$ film. Such an enhancement of the built-in potential could facilitate the photo-generated excitons dissociating into free charge carriers and benefit the transport of charge carriers to the electrode. Thus, we have supplied an efficient electron conducting layer not only for the photovoltaic community but also for other photoelectronic devices.
\end{abstract}

\section{Introduction}

Owing to the great advantages of regulating the work function of an electrode and improving the charge carrier injection and extraction, buffer layers have been extensively utilized in organic-based thin-film optoelectronic devices, including organic solar cells (OSCs), organic light-emitting diodes (OLEDs) and perovskite solar cells (PSCs). ${ }^{1-6}$ In buffer layers, titanium oxide $\left(\mathrm{TiO}_{x}\right)$, zinc oxide $(\mathrm{ZnO})$ and cesium carbonate $\left(\mathrm{Cs}_{2} \mathrm{CO}_{3}\right)$ have been incorporated into optoelectronic devices frequently as an electron transport layer and can improve the device performance effectively. ${ }^{7-10}$ In particular, $\mathrm{ZnO}$ is a promising candidate due to its relatively high electron mobility, environmental stability, and transmissivity in the visible region. ${ }^{\mathbf{1 1 - 1 9}}$ There are already plenty of studies about $\mathrm{ZnO}$ use in organic solar cells, such as ZnO nanowires, ZnO nanorods, ZnO nanoparticles and $\mathrm{ZnO}$ films, ${ }^{15-18}$ which are all good for the device performance. In a previous study, K. Kim et al. increased the power conversion efficiency (PCE) of OSCs from $7.66 \%$ to $7.96 \%$ by atomic layer deposition of $\mathrm{ZnO}$ film. ${ }^{12} \mathrm{~S}$. Cowan and his coworkers improved the performance of OSCs to $5.93 \%$ by modifying the surface of ZnO film. ${ }^{13}$ Furthermore, W. Qiu et al.

${ }^{a}$ Physics Department, Zhejiang Normal University, Zhejiang 321004, China. E-mail: chidan@zjnu.edu.cn

${ }^{b}$ Key Laboratory of Semiconductor Materials Science, Institute of Semiconductors, Chinese Academy of Sciences, Beijing 100083, People's Republic of China. E-mail: wangzj@semi.ac.cn; qsc@semi.ac.cn

$\dagger$ Electronic supplementary information (ESI) available. See DOI: $10.1039 / \mathrm{c} 6 \mathrm{ra} 27543 \mathrm{e}$ improved the PCE of PSCs by using PCBM/ZnO as a double electron transport layer. ${ }^{\mathbf{1 4}}$ Besides the complexity of these methods, the thickness of the $\mathrm{ZnO}$ film in the above studies is more than $45 \mathrm{~nm}$, which will suppress the light harvesting of the active layer in the UV region. The thick film would also increase the transport length of the charge carriers, as a result, and enhance the according recombination possibilities.

In light of these issues, we propose a solution process to fabricate an ultra-thin $\mathrm{ZnO}$ film, which offers an excellent platform for optimizing the performance of the OSCs without sacrificing the light absorption efficiency. In this work, $\mathrm{ZnO}$ films with various thicknesses in the range of 0 to $28.1 \mathrm{~nm}$ were introduced in the OSCs, and the device with $4 \mathrm{~nm} \mathrm{ZnO}$ showed the highest PCE of $7.51 \%$, much higher than that of the reference device with a conventional ZnO film (6.33\%). We observe that the dramatically improved PCE is mainly due to an increase of $0.5 \%$ in $V_{\mathrm{OC}}, 13.9 \%$ in $J_{\mathrm{SC}}$ and $3.6 \%$ in fill factor (FF). Further experimental investigations show that the $\mathrm{ZnO}$ film improves the device performance by the following aspects: enhancing the built-in potential $\left(V_{\mathrm{bi}}\right)$ of the device and increasing the shunt resistance of the system by facilitating the exciton dissociation efficiency and reducing the charge carrier recombination in the ZnO film.

\section{Results and discussion}

The solution-processed ultra-thin $\mathrm{ZnO}$ films were produced using a carbon free aqueous $\mathrm{Zn}(\mathrm{OH})_{x}\left(\mathrm{NH}_{3}\right)_{y}{ }^{(2-x)+}$ solution, ${ }^{20-23}$ and the thicknesses were gauged as 2.8, 4.0, 5.0 and 5.6 nm with the $\mathrm{ZnO}$ concentration increasing from $0.04 \mathrm{~mol} \mathrm{~L}^{-1}$ to $0.07 \mathrm{~mol}$ 
$\mathrm{L}^{-1}$, which are measured by TEM in ref. 22 . The $28.1 \mathrm{~nm}$ thick ZnO film was fabricated using conventional zinc acetate dehydrate precursor solution. ${ }^{8}$ Fig. 1a shows the transmittance spectra of the as-prepared $\mathrm{ZnO}$ films on quartz glass. In order to make a better comparison, the absorption of the quartz glass has been dubbed out. The ultra-thin ZnO films present high light transmissivity. The transmittance of the $\mathrm{ZnO}$ films is in excess of $99 \%$ from $350 \mathrm{~nm}$ to $800 \mathrm{~nm}$ and decreases slightly with the increase of the $\mathrm{ZnO}$ thickness. However, the light transmissivity of the thick $\mathrm{ZnO}$ film is lower than those of the ultra-thin $\mathrm{ZnO}$ films in the range of $200 \mathrm{~nm}$ to $800 \mathrm{~nm}$, which could suppress the light absorption efficiency of the active layer in the constructed OSCs. Fig. 1b shows the ultraviolet photoelectron spectroscopy (UPS) spectra of ITO and ZnO films on ITO glass (ZnO-ITO) with different thicknesses. The work function (WF) value can be calculated from the secondary electron cutoff region of the five samples. The value of ITO is $4.4 \mathrm{eV}$, while those of the ultra-thin $\mathrm{ZnO}-\mathrm{ITO}$ and $28.1 \mathrm{~nm} \mathrm{ZnO}-$ ITO are $3.7 \mathrm{eV}$ and $4.1 \mathrm{eV}$. Obviously, the WF values of ultra-thin ZnO-ITO and $28.1 \mathrm{~nm} \mathrm{ZnO}-\mathrm{ITO}$ are moved upwards by $0.7 \mathrm{eV}$ and $0.3 \mathrm{eV}$ in regard to the pristine ITO, respectively. The low WF values of ZnO-ITO could make the material form good ohmic contact with the active layer. As is known, $V_{\mathrm{OC}}$ is mostly affected by the difference between the highest occupied molecular orbital (HOMO) of the donor materials and the lowest unoccupied molecular orbital (LUMO) of the acceptor materials and the WF difference between the cathode and anode. ${ }^{24-27}$ Theoretically, the larger the WF difference the electrodes have, the larger the $V_{\mathrm{OC}}$ presented by the OSCs.
Moreover, the lower WF of the ultra-thin ZnO-ITO can increase the $V_{\mathrm{bi}}$ of the devices, which can be beneficial to improve the charge carrier extraction efficiency and reduce the recombination losses. As revealed by the UPS spectra, the thickness of the ultra-thin $\mathrm{ZnO}$ has no effect on the WF of ZnO-ITO, which is mainly affected by the synthesis approach. To be significant, the lower WFs of the ultra-thin $\mathrm{ZnO}$ compared to the conventional $\mathrm{ZnO}$ film make it superior.

Fig. 1c displays the cross-sectional scanning electron microscopy (SEM) image of the device with a structure of ITO/ ultra-thin $\mathrm{ZnO} / \mathrm{PBDTTT}-\mathrm{CF}: \mathrm{PC}_{70} \mathrm{BM} / \mathrm{MoO}_{3} / \mathrm{Ag}$ by $0^{\circ}$ titled view. It can be clearly seen that the $\mathrm{ZnO}$ film is ultra-thin. Such a structure could reduce the inefficient light blocking by the $\mathrm{ZnO}$ layer, because of the fact that the incident light is from the ITO direction. The $\mathrm{MoO}_{3} / \mathrm{Ag}$ layer facilitates the hole collection and the $\mathrm{ZnO}$ layer is applied for harvesting the electrons generated in the active layer. As exhibited in Fig. $\mathrm{S} 1, \uparrow$ we can see that the ultra-thin $\mathrm{ZnO}$ film is very smooth. The smoothness of the $\mathrm{ZnO}$ film, which helps to generate good interfacial contact between the cathode and active layer, can decrease the interfacial traps. Therefore, the electron transporting into the interface of the $\mathrm{ZnO}$ and active layer can be extracted by the $\mathrm{ZnO}$ layer and collected by the cathode successfully. Fig. 1d presents the X-ray photoelectron spectroscopy (XPS) spectra of the $4.0 \mathrm{~nm}$ ultra-thin $\mathrm{ZnO}$ film and $28.1 \mathrm{~nm} \mathrm{ZnO}$ film, which exhibits strong $\mathrm{Zn} 2 \mathrm{p}_{1 / 2}, \mathrm{Zn} 2 \mathrm{p}_{3 / 2}$ and $\mathrm{O} 1 \mathrm{~s}$ peaks at around $1045 \mathrm{eV}, 1022 \mathrm{eV}$ and $531 \mathrm{eV}$, respectively. This measurement reveals that the $\mathrm{ZnO}$ films have no difference in the material aspect. Moreover, it has been reported that the ultra-thin $\mathrm{ZnO}$

\section{(a)}
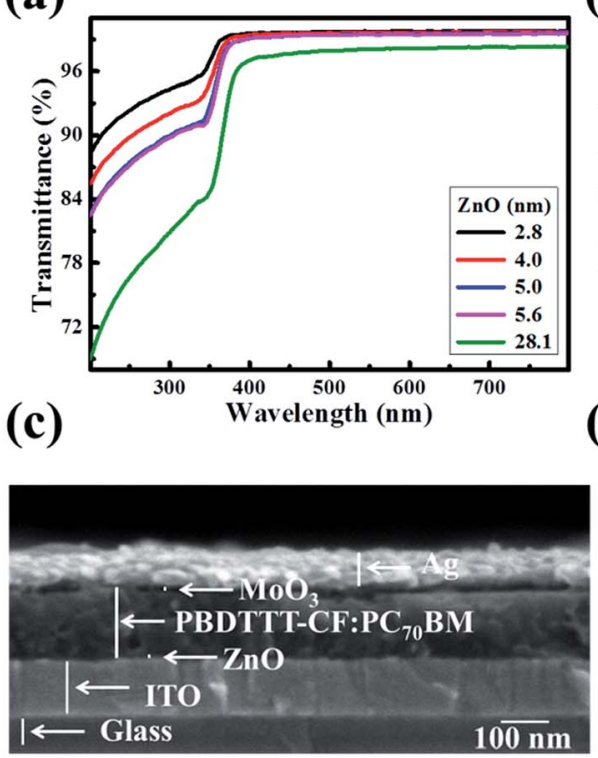

(b)

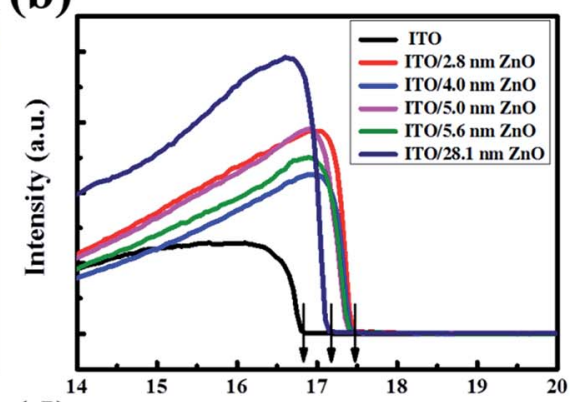

(d)

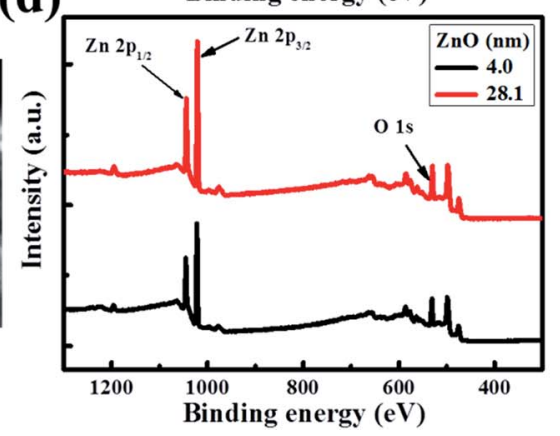

Fig. 1 (a) Transmittance spectra of the ZnO films on quartz glass with different thicknesses. (b) UPS spectra of ITO and ZnO films with different thicknesses on ITO glass. The spectra show the energy region of the secondary electron cut-off. (c) The cross-sectional scanning electron microscopy image of the device with a structure of ITO/ultra-thin $\mathrm{ZnO} / \mathrm{PBDTTT}-\mathrm{CF}: \mathrm{PC}_{70} \mathrm{BM} / \mathrm{MoO}_{3} / \mathrm{Ag}$ by $0^{\circ}$ titled view. (d) $\mathrm{X}$-ray photoelectron spectroscopy (XPS) spectra for Zn 2p1/2, Zn 2p3/2 and O 1s. 
film has a highly uniform and polycrystalline nature. ${ }^{22}$ Due to the advantages of the ultra-thin $\mathrm{ZnO}$ film, we utilized it as an electron transport layer to optimize the performance of the OSCs herein, and a device with $28.1 \mathrm{~nm} \mathrm{ZnO}$ was fabricated as a reference.

Fig. 2a presents the current density-voltage $(J-V)$ curves of the relevant devices with different thicknesses of the $\mathrm{ZnO}$ films under illumination, and the corresponding performance parameters are summarized in Table 1 , including the ideality factor $(n)$ and the reverse saturation current density $\left(J_{0}\right)$. All the devices with $4 \mathrm{~nm}$ to $5.6 \mathrm{~nm}$ ultra-thin $\mathrm{ZnO}$ film performed better than the device with $28.1 \mathrm{~nm}$ thick $\mathrm{ZnO}$ film. The OSC works best when the thickness of the $\mathrm{ZnO}$ film is $4.0 \mathrm{~nm}$. By introducing $4 \mathrm{~nm} \mathrm{ZnO}$ into the device and comparing with the conventional device, the $V_{\mathrm{OC}}, J_{\mathrm{SC}}, \mathrm{FF}$ and PCE are prominently enhanced from $0.731 \mathrm{~V}$ to $0.735 \mathrm{~V}, 14.20 \mathrm{~mA} \mathrm{~cm}^{-2}$ to $16.18 \mathrm{~mA}$ $\mathrm{cm}^{-2}, 61.0 \%$ to $63.2 \%$ and $6.33 \%$ to $7.51 \%$, respectively. The improved properties are mainly due to the enhancement of about $13.9 \%$ in $J_{\mathrm{SC}}$. Fig. $2 \mathrm{a}$ and Table 1 show that the performances of the devices with $4 \mathrm{~nm}$ to $5.6 \mathrm{~nm} \mathrm{ZnO}$ films are better than those of the devices without $\mathrm{ZnO}$ and with $28.1 \mathrm{~nm} \mathrm{ZnO}$ film. The device parameters with different thicknesses of $\mathrm{ZnO}$ film are shown in Fig. S2. $\dagger$ The $J-V$ curves of devices with and without $\mathrm{ZnO}$ films under darkness are presented in Fig. S3. $\dagger$ The $n$ and $J_{0}$, which could characterize the property of the diode, can be extracted from the $J-V$ curves under darkness by fitting the data into the simplified Shockley eqn (1):

$$
V_{\mathrm{OC}}=\frac{n k_{\mathrm{B}} T}{q} \ln \left(\frac{J_{\mathrm{SC}}}{J_{0}}\right)
$$
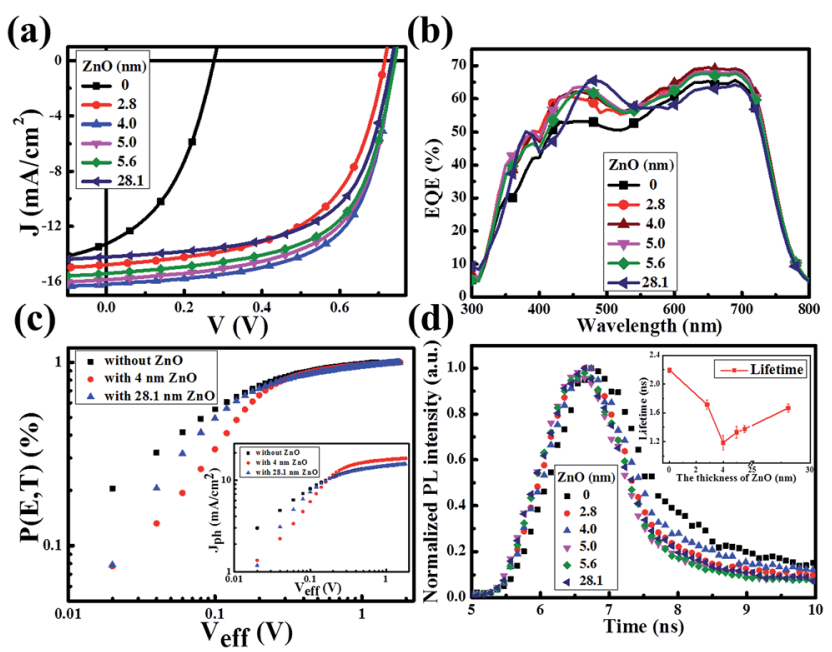

Fig. 2 (a) J-V curves of the devices with different thicknesses of $\mathrm{ZnO}$ film under illumination of AM1.5 G, $100 \mathrm{~mW} \mathrm{~cm}^{-2}$. (b) EQE spectra of the devices with different thicknesses of $\mathrm{ZnO}$ film. (c) $P[E, T]-V_{\text {eff }}$ curves of the devices without $\mathrm{ZnO}$ and with $4 \mathrm{~nm}$ and $28.1 \mathrm{~nm} \mathrm{ZnO}$ film. The inset shows the $J_{\mathrm{ph}}-V_{\text {eff }}$ curves of the devices without $\mathrm{ZnO}$ and with a $4 \mathrm{~nm}$ and $28.1 \mathrm{~nm} \mathrm{ZnO}$ film. (d) Transient PL decays of the structures of ITO/ZnO/PBDTTT-CF:PC ${ }_{70} \mathrm{BM}$ with thicknesses of the $\mathrm{ZnO}$ film. The inset gives the dependence of the lifetime on the thickness of the $\mathrm{ZnO}$ film.
The approach of extracting the parameters has been detailed previously. ${ }^{28-31}$ As revealed in Table 1, the $J_{0}$ decreases about 1 order of magnitude from the device with $28.1 \mathrm{~nm} \mathrm{ZnO}$ to the device with $4 \mathrm{~nm}$ ultra-thin $\mathrm{ZnO}$. Therefore the $V_{\mathrm{OC}}$ is distinctly improved according to the simplified Shockley equation. The reduced $J_{0}$ together with the reduced $n$ implies that the ultrathin $\mathrm{ZnO}$ film could inhibit charge carrier recombination, thus suppressing the photogenerated charge carrier loss. Obviously, all the devices with a ZnO film perform better than the device without ZnO (Table 1). This could be proved by the increased external quantum efficiency (EQE) spectra shown in Fig. 2b. The EQE values of the devices with ultra-thin $\mathrm{ZnO}$ films are higher than that of the device with a $28.1 \mathrm{~nm} \mathrm{ZnO}$ film in the range from $550 \mathrm{~nm}$ to $800 \mathrm{~nm}$ and that of the device without $\mathrm{ZnO}$ film in the whole scanned wavelength range, which is consistent with the information in Fig. 2a and Table 1. Fig. 1a shows that the thick ZnO film absorbs more light from $300 \mathrm{~nm}$ to $800 \mathrm{~nm}$ compared with the ultra-thin $\mathrm{ZnO}$ films, especially in the range from $300 \mathrm{~nm}$ to $500 \mathrm{~nm}$. Therefore, the device fabricated with a thick $\mathrm{ZnO}$ film will impede the absorption of the active layer and reduce the EQE of the device in the range from $300 \mathrm{~nm}$ to $500 \mathrm{~nm}$. As a result, the peak in the EQE spectrum of the device with a thick $\mathrm{ZnO}$ film shifts toward longer wavelengths and the migration distance is about $25 \mathrm{~nm}$. As demonstrated in Table 1, the ultra-thin ZnO films with thicknesses from $2.8 \mathrm{~nm}$ to $5.6 \mathrm{~nm}$ show an improved FF of the OSCs.

In order to further investigate the influence of an ultra-thin $\mathrm{ZnO}$ film on the exciton generation and dissociation, the maximum exciton generation rate $\left(G_{\max }\right)$ and exciton dissociation probability $(P[E, T])$ of the device are particularly extracted based on the method previously reported. ${ }^{32-35}$ Fig. 2c displays the dependence of $P[E, T]$ on the effective voltage $\left(V_{\text {eff }}\right)$ of the devices with a $4 \mathrm{~nm}$ and $28.1 \mathrm{~nm} \mathrm{ZnO}$ film and the device without a $\mathrm{ZnO}$ film. The inset shows the dependence of the photocurrent density $\left(J_{\mathrm{ph}}\right)$ of these three devices on $V_{\text {eff. }}$ Herein, $J_{\mathrm{ph}}$ is described by $J_{\mathrm{ph}}=J_{\mathrm{L}}-J_{\mathrm{D}}$, where $J_{\mathrm{L}}$ and $J_{\mathrm{D}}$ are the current densities under illumination and under darkness, respectively. $V_{\text {eff }}$ is given by $V_{\text {eff }}=V_{0}-V_{\mathrm{a}}$, where $V_{0}$ is the voltage when $J_{\mathrm{ph}}$ is equal to 0 and $V_{\mathrm{a}}$ is the applied voltage. The value of the saturation photocurrent density $J_{\text {sat }}$ can be directly extracted from the inset, and $G_{\max }$ could be derived by $J_{\text {sat }}=q G_{\max } L$, if we hypothesise that all of the photogenerated excitons are dissociated and contribute to the current at high $V_{\text {eff }}$, where $q$ is the electronic charge and $L$ is the thickness of the active layer. The values of $G_{\max }$ for the device without $\mathrm{ZnO}$ and the devices with $4.0 \mathrm{~nm}$ and $28.1 \mathrm{ZnO}$ are $9.02 \times 10^{27} \mathrm{~m}^{-3} \mathrm{~s}^{-1}\left(J_{\text {sat }}=14.58 \mathrm{~mA}\right.$ $\left.\mathrm{cm}^{-2}\right), 10.72 \times 10^{27} \mathrm{~m}^{-3} \mathrm{~s}^{-1}\left(J_{\text {sat }}=17.31 \mathrm{~mA} \mathrm{~cm}^{-2}\right)$ and $9.98 \times$ $10^{27} \mathrm{~m}^{-3} \mathrm{~s}^{-1}\left(J_{\text {sat }}=15.00 \mathrm{~mA} \mathrm{~cm}{ }^{-2}\right)$, respectively. The evident improvement of $J_{\text {sat }}$ (about 15.4\%) implies that an ultra-thin $\mathrm{ZnO}$ film is more beneficial to the transport of the charge carriers, and it is impressively larger than that of the $28.1 \mathrm{~nm}$ thick $\mathrm{ZnO}$ film, therefore facilitating the enhancement of $J_{\mathrm{SC}}$. As revealed by Fig. 2c, the exciton dissociation probability can be described as $J_{\mathrm{ph}}=q G_{\max } P[E, T] L$. Thus, the relevant values of $P$ $[E, T]$ at any $V_{\text {eff }}$ could be obtained by the normalized current density $J_{\mathrm{ph}} / J_{\text {sat }}$. It is calculated that the values of $P[E, T]$ increased from $80.4 \%$ for the device without $\mathrm{ZnO}$ to $95.1 \%$ and $93.0 \%$ for 
Table 1 Parameters of the devices with different $\mathrm{ZnO}$ film thicknesses

\begin{tabular}{|c|c|c|c|c|c|c|}
\hline $\mathrm{ZnO}(\mathrm{nm})$ & $V_{\mathrm{OC}}(\mathrm{V})$ & $J_{\mathrm{SC}}\left(\mathrm{mA} \mathrm{cm}^{-2}\right)$ & $\mathrm{FF}(\%)$ & $\operatorname{PCE}\left(\mathrm{PCE}_{\text {ave }}\right)(\%)$ & $n$ & $J_{0}\left(\mathrm{~mA} \mathrm{~cm}{ }^{-2}\right)$ \\
\hline 0 & 0.277 & 13.26 & 41.6 & $1.53(1.36)$ & 1.97 & $6.30 \times 10^{-3}$ \\
\hline 2.8 & 0.713 & 14.75 & 57.3 & $6.02(5.98)$ & 1.68 & $3.85 \times 10^{-7}$ \\
\hline 5.0 & 0.737 & 15.84 & 61.8 & $7.21(7.14)$ & 1.59 & $8.18 \times 10^{-8}$ \\
\hline 5.6 & 0.739 & 15.39 & 61.4 & $6.98(6.88)$ & 1.64 & $2.47 \times 10^{-7}$ \\
\hline 28.1 & 0.731 & 14.20 & 61.0 & $6.33(6.27)$ & 1.67 & $1.57 \times 10^{-7}$ \\
\hline
\end{tabular}

the devices with the $4.0 \mathrm{~nm}$ and $28.1 \mathrm{~nm} \mathrm{ZnO}$ films, which demonstrates that an ultra-thin $\mathrm{ZnO}$ film could facilitate the photogenerated excitons to dissociate into free charge carriers efficiently.

To further explore the influence of the $\mathrm{ZnO}$ film on exciton dissociation experimentally, we performed transient photoluminescence (PL) measurements for these devices. As shown in Fig. 2d, the samples with an ultra-thin $\mathrm{ZnO}$ film present a faster decay in comparison with the sample with a $28.1 \mathrm{~nm}$ thick $\mathrm{ZnO}$ film, which demonstrates that the ultra-thin $\mathrm{ZnO}$ film promotes the separation of the photogenerated excitons. For analyzing these results in more detail, we fit the decay curves using a biexponential model. The calculated lifetimes are $2.19 \mathrm{~ns}$ (without ZnO), $1.72 \mathrm{~ns}$ (2.8 nm ZnO), $1.18 \mathrm{~ns}$ (4.0 nm ZnO), 1.33 ns (5.0 nm ZnO), $1.37 \mathrm{~ns}(5.6 \mathrm{~nm} \mathrm{ZnO})$ and $1.67 \mathrm{~ns}(28.1 \mathrm{~nm}$ $\mathrm{ZnO}$ ). The lifetime as a function of the $\mathrm{ZnO}$ film thickness is displayed as the inset in Fig. 2d. It could be noted that the tendency of the transient PL lifetime $v s$. ZnO film thickness matches well with the trend in the analysis of $P[E, T]$.

In order to investigate the functionality of the $\mathrm{ZnO}$ film, the device with a structure of ITO/ZnO/PBDTTT-CF:PC ${ }_{70} \mathrm{BM} / \mathrm{Ca} / \mathrm{Al}$ was fabricated and the electron mobility is calculated from the space charge limited current (SCLC) method according to eqn (2):

$$
J=\frac{9}{8} \varepsilon_{0} \varepsilon_{\mathrm{r}} \mu_{\mathrm{e}} \frac{V^{2}}{L^{3}}
$$

where $J$ is the current density, $\varepsilon_{0}$ is the permittivity of vacuum, and $\varepsilon_{\mathrm{r}}$ is the relative permittivity of the organic material. Herein, we use $\varepsilon_{\mathrm{r}}$ with a value of 3 for ease of calculation. ${ }^{28} V$ is the effective potential drop inside the active layer. $\mu_{\mathrm{e}}$ is the electron mobility and $L$ is the thickness of active layer. The $\ln J v s .2 \ln V$ curves are presented in Fig. $3 \mathrm{a}$ and the electron mobilities with different thicknesses of the $\mathrm{ZnO}$ film are shown in Fig. $3 \mathrm{~b}$. The electron mobility could be calculated as $1.41 \times 10^{-5} \mathrm{~cm}^{2} \mathrm{~V}^{-1} \mathrm{~s}^{-1}$, $3.13 \times 10^{-5} \mathrm{~cm}^{2} \mathrm{~V}^{-1} \mathrm{~s}^{-1}, 7.58 \times 10^{-5} \mathrm{~cm}^{2} \mathrm{~V}^{-1} \mathrm{~s}^{-1}, 6.10 \times 10^{-5}$ $\mathrm{cm}^{2} \mathrm{~V}^{-1} \mathrm{~s}^{-1}, 4.96 \times 10^{-5} \mathrm{~cm}^{2} \mathrm{~V}^{-1} \mathrm{~s}^{-1}$ and $3.93 \times 10^{-5} \mathrm{~cm}^{2} \mathrm{~V}^{-1}$ $\mathrm{s}^{-1}$. Obviously, the electron mobilities of the devices with a $4 \mathrm{~nm}$ to $5.6 \mathrm{~nm}$ ultra-thin $\mathrm{ZnO}$ film are higher than that of the device with a $28.1 \mathrm{~nm}$ thick $\mathrm{ZnO}$ film. This is due to the highly uniform and polycrystalline nature of the ultra-thin $\mathrm{ZnO}$ film. ${ }^{22}$ The thick ZnO film (28.1 nm) could increase the transport length of the charge carriers, as a result, and enhance the according recombination possibilities, thus reducing the electron mobility. The lower electron mobility of the device with a $2.8 \mathrm{~nm}$ ultra-thin $\mathrm{ZnO}$ film could originate from the incomplete coverage of the $\mathrm{ZnO}$ film on ITO. The ZnO transistor was fabricated via the same aqueous carbon-free metal oxide precursor route showing an electron mobility of up to $11 \mathrm{~cm}^{2} \mathrm{~V}^{-1} \mathrm{~s}^{-1}$, which means that the electron mobility in the ultra-thin $\mathrm{ZnO}$ film is high enough for the electron transport from the active layer to cathode. The detailed results of the $\mathrm{ZnO}$ transistor are shown in ref. 22 .

Collectively, we have shown that the device with an ultra-thin ZnO film performs better than the device with a conventional $\mathrm{ZnO}$ film. To get more information on the charge transfer mechanism of the superior device, impedance spectroscopy was recorded. As revealed by Fig. 4a, all of the spectra present the standard semicircle feature of a Nyquist plot, and the semicircle diameters of the devices with an ultra-thin $\mathrm{ZnO}$ film are larger than that of the device without $\mathrm{ZnO}$. When the $\mathrm{ZnO}$ thickness is $4 \mathrm{~nm}$, the performance of the device reaches the maximum. To further analyze the spectra, we used a typical equivalent circuit shown in the inset to fit these spectra. ${ }^{36-38}$ The fitted curves are in good agreement with the measured ones, indicating the correctness of the simulation. In the equivalent circuit, we use $R_{1}$ to represent the transfer recombination component from the active layer to the $\mathrm{MoO}_{3} / \mathrm{Ag}$ top electrode and $R_{2}$ as the transfer recombination component from the active layer to $\mathrm{ZnO} / \mathrm{ITO}$. These two are connected with a series resistance $\left(R_{\mathrm{s}}\right)$ and the extracted data are given in Table S1. $\dagger R_{1}$ is invariable with the change in $\mathrm{ZnO}$ thickness, owing to the same architecture feature of the active layer and $\mathrm{MoO}_{3} / \mathrm{Ag}$ electrode in these devices. $R_{\mathrm{s}}$ decreases with the thickening of $\mathrm{ZnO}$ and reaches the minimum when the thickness is $4 \mathrm{~nm}$. As we increase the thickness further, $R_{\mathrm{S}}$ begins to increase. This feature matches well with the feature of the device performance, which indicates that reduction of $R_{\mathrm{s}}$ is responsible for the performance improvement, particularly in the FF..$^{33,39-43}$ The optimized $\mathrm{ZnO}$ thickness is beneficial for reducing the charge transfer resistance. Alternatively, $R_{2}$ shows an increasing feature with the enlargement of the $\mathrm{ZnO}$ thickness and reaches the maximum when the thickness is $4 \mathrm{~nm}$. Generally, $R_{2}$ represents the shunt resistance at the ITO/ZnO/active layer, and a large value of $R_{2}$ usually shows a lower possibility of charge recombination. ${ }^{44-46} \mathrm{~A}$ too thin film of $\mathrm{ZnO}$ would have a low ability to conduct the electrons to ITO, due to the imperfect coverage that induces a high recombination possibility at the interface of the ITO/ $\mathrm{ZnO} /$ active layer. A too thick film of $\mathrm{ZnO}$ would have a large recombination possibility in $\mathrm{ZnO}$, owing to the long charge transfer length. The charge transfer recombination could also be monitored by IS under different applied potentials and shows an increasing feature with the bias increasing from $0.1 \mathrm{~V}$ to $0.7 \mathrm{~V}$, along with a decreased diameter of the semicircles. This is due to the fact that the density of the charge carriers 
(a)

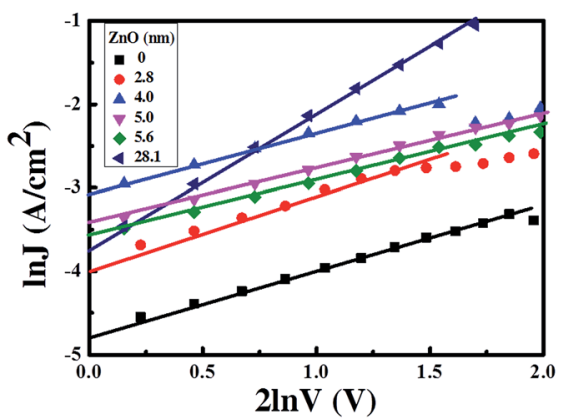

(b)

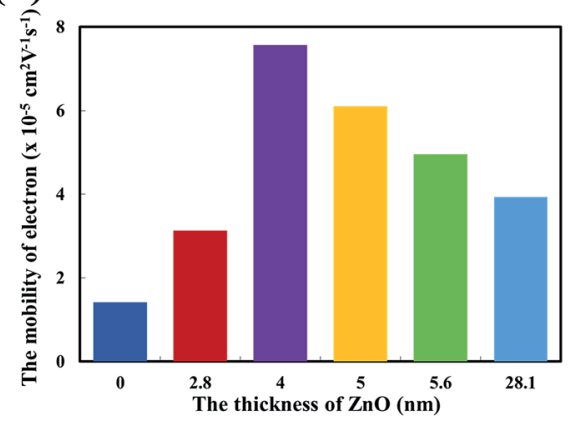

Fig. 3 (a) The In J vs. 2 In V curves with different thicknesses of the ZnO film. (b) Electron mobility of devices with different thicknesses of the ZnO film.

inside the device increases tremendously under a high positive bias, thus more holes and electrons recombine with each other.

To support the analysis of the improved performance of devices with a $\mathrm{ZnO}$ film, we calculated the $V_{\mathrm{bi}}$ of the devices with different $\mathrm{ZnO}$ thicknesses from the Mott-Schottky analysis (Fig. 4b). According to eqn (3), we can estimate the $V_{\mathrm{bi}}$ using the following equation: ${ }^{45}$

$$
\frac{1}{C^{2}}=\frac{2\left(V_{\mathrm{bi}}-V\right)}{A^{2} e \varepsilon \varepsilon_{0} N_{\mathrm{A}}}
$$

where $C$ is the capacitance of the device, $V$ is the applied voltage, $A$ is the device area, $e$ is the electronic charge, $\varepsilon$ is the dielectric constant of the materials, $\varepsilon_{0}$ is the permittivity of vacuum and $N_{\mathrm{A}}$ is the doping concentration. The measurements were recorded at a frequency of $1 \mathrm{kHz}$ for extracting $V_{\mathrm{bi}}$. As revealed in Fig. $4 \mathrm{~b}$, the $V_{\mathrm{bi}}$ of devices with the $\mathrm{ZnO}$ thickness varied from $0 \mathrm{~nm}$ to $5.6 \mathrm{~nm}$ is $0.416 \mathrm{~V}, 0.710 \mathrm{~V}, 0.722 \mathrm{~V}, 0.728 \mathrm{~V}$ and $0.738 \mathrm{~V}$. After the introduction of an ultra-thin $\mathrm{ZnO}$ film, the $V_{\mathrm{bi}}$ of the device is improved, in agreement with the WF value difference between the cathode and anode, thus leading to an enhancement in the $V_{\mathrm{OC}}$ of the device. As shown in Table 1 , the $V_{\mathrm{OC}}$ of the device with $4 \mathrm{~nm} \mathrm{ZnO}$ is 2.7 times higher than that of the device without ZnO. In addition, the enhanced $V_{\mathrm{bi}}$ could also facilitate the photogenerated excitons to separate into charge carriers and thereby increase the $J_{\mathrm{SC}}$ of the device, consistent with the results summarized in Table 1 . Moreover, the bigger $V_{\mathrm{bi}}$ will help the charge carriers transport more quickly in the active layer, because the bigger $V_{\mathrm{bi}}$ enhances the electric-field strength and will accelerate the carrier transport. As a result, the ultrathin $\mathrm{ZnO}$ film enhances the $V_{\mathrm{bi}}$ of the device and thus improves the device performance.

We have also fabricated OSCs with P3HT using a thick ZnO layer and $4 \mathrm{~nm} \mathrm{ZnO}$ layer. The PCEs of P3HT:PC ${ }_{60} \mathrm{BM}$ fabricated using a thick $\mathrm{ZnO}$ layer and $4 \mathrm{~nm} \mathrm{ZnO}$ layer as the electron transport layer are $2.22 \%$ and $2.63 \%$, respectively. The $J-V$ curves are shown in Fig. S6. $\dagger$ It can be demonstrated from the $J-$ $V$ curves that the device of $\mathrm{P} 3 \mathrm{HT}: \mathrm{PC}_{60} \mathrm{BM}$ with the ultra-thin $\mathrm{ZnO}$ film works better than that with the thick $\mathrm{ZnO}$ film. Therefore, the ultra-thin $\mathrm{ZnO}$ film can work well as the electron transport layer for P3HT.

\section{Conclusion}

In summary, a highly efficient PBDTTT-CF:PC ${ }_{70} \mathrm{BM}$ solar cell incorporated with an ultra-thin $\mathrm{ZnO}$ film has been fabricated. The ultra-thin ZnO film can improve the device performance in the following aspects: improving the built-in potential of the device by adjusting the work function of ITO; facilitating the (a)

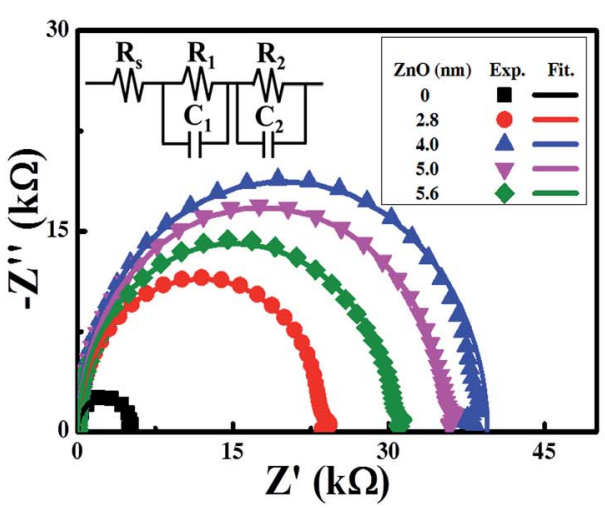

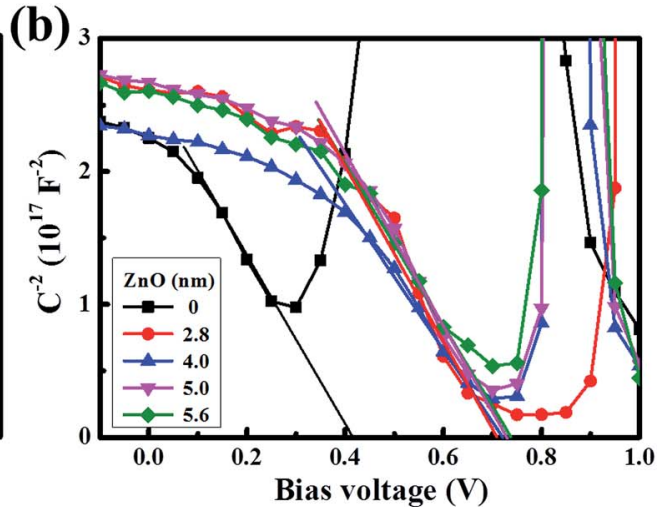

Fig. 4 (a) Impedance spectra of the devices with different thicknesses of the ZnO film. (b) Built-in potential (Mott-Schottky plot) of devices with different thicknesses of the $\mathrm{ZnO}$ film. 
exciton dissociation; promoting the charge carrier transportation; reducing the shunt resistance of the device. Therefore, an impressive enhancement in $V_{\mathrm{OC}}$ and $J_{\mathrm{SC}}$ has been achieved. The maximum PCE of $7.51 \%$ is attained for the device with $4.0 \mathrm{~nm} \mathrm{ZnO}$. In addition, the proposed carbon free aqueous process for preparing the ultra-thin $\mathrm{ZnO}$ is environmentally friendly and could be widely applied in solar cells and LEDs etc.

\section{Experimental}

\section{Device fabrication}

All devices were fabricated on indium tin oxide (ITO) patterned glass substrates, which were cleaned with detergent and sonicated in deionized water, acetone, and then isopropanol for $10 \mathrm{~min}$. Then, the ITO substrates were exposed to $\mathrm{O}_{2}$ plasma for 6 min prior to spin-coating the $\mathrm{ZnO}$ thin films at $2000 \mathrm{rpm}$ for $30 \mathrm{~s}$. The precursor solution for fabricating the ultra-thin $\mathrm{ZnO}$ films was prepared by dissolving zinc oxide hydrate $\left(\mathrm{ZnO} \cdot x \mathrm{H}_{2} \mathrm{O}\right.$, $97 \%$, Sigma-Aldrich) in ammonium hydroxide (28-30\%, SigmaAldrich) to molar concentrations in the range of $0.04-0.07 \mathrm{M}$. As-prepared solutions were then stirred rigorously at room temperature for $8 \mathrm{~h}$ and became a clear transparent $\mathrm{Zn}$ ammonium complex $\left(\mathrm{Zn}(\mathrm{OH})_{x}\left(\mathrm{NH}_{3}\right)_{y}{ }^{(2-x)+}\right)$ based solution. ${ }^{20-23}$ $\mathrm{ZnO} \cdot x \mathrm{H}_{2} \mathrm{O}$ dissolved quickly at a low temperature. Next, the $\mathrm{ZnO}$ coated substrates were annealed at $200{ }^{\circ} \mathrm{C}$ for $60 \mathrm{~min}$ in air, and then taken into a nitrogen-filled glove box. The active blend layer of PBDTTT-CF (poly[1-(6-\{4,8-bis[(2-ethylhexyl)oxy]-6-methylbenzo[1,2- $b$ :4,5- $\left.b^{\prime}\right]$ dithiophen-2-yl\}-3-fluoro-4-methylthieno[3,4- $\left.b\right]$ thiophen-2-yl)-1-octanone ]): $\mathrm{PC}_{70} \mathrm{BM}\left([6,6]-\right.$ phenyl- $\mathrm{C}_{70}$-butyric acid methyl ester) was spin-coated onto the substrates at $800 \mathrm{rpm}$ for $90 \mathrm{~s}$. The PBDTTT-CF: $\mathrm{PC}_{70} \mathrm{BM}$ solution consisted of $10 \mathrm{mg} \mathrm{m}^{-1}$ PBDTTT-CF and $15 \mathrm{mg} \mathrm{ml}{ }^{-1} \mathrm{PC}_{70} \mathrm{BM}$ in $o$-dichlorobenzene (ODCB) with 3\% 1,8-diiodooctane (1,8-DIO). Finally, a $2 \mathrm{~nm}$ $\mathrm{MoO}_{3}$ and $80 \mathrm{~nm} \mathrm{Ag}$ electrode were evaporated at a base pressure of $9.0 \times 10^{-5} \mathrm{~Pa}$ through a shadow mask. The diameters of oxygen and molybdenum are $0.132 \mathrm{~nm}$ and $0.272 \mathrm{~nm}$, respectively. Therefore, the $2 \mathrm{~nm} \mathrm{MoO}_{3}$ layer is thick enough to cover the entire surface of the active layer. The ultra-thin $\mathrm{MoO}_{3}$ layer can regulate and control the work function of $\mathrm{Ag}$. The work function of $\mathrm{Ag}$ is $4.3 \mathrm{eV}$ which is improper as the anode, while the $\mathrm{MoO}_{3}$ layer with the high work function of $5.4 \mathrm{eV}$ combined with $\mathrm{Ag}$ will be perfect as the anode electrode. However, the conductivity of the $\mathrm{MoO}_{3}$ layer is poor. The thick $\mathrm{MoO}_{3}$ layer will reduce the hole extraction rate and thus reduce the device performance. Since the $2 \mathrm{~nm} \mathrm{MoO}_{3}$ layer is thick enough to realize good performance for ITO/ZnO/PBDTTT-CF: $\mathrm{PC}_{70} \mathrm{BM} / \mathrm{MoO}_{3} / \mathrm{Ag}$, we just deposited the $2 \mathrm{~nm} \mathrm{MoO}_{3}$ layer as the hole transport layer for our organic solar cell.

\section{Device measurements}

The current density-voltage characteristics of these devices were measured with a computer-controlled Keithley 2400 under AM 1.5 illumination with an intensity of $100 \mathrm{~mW} \mathrm{~cm}^{-2}$ in a $\mathrm{N}_{2}$ atmosphere ( $450 \mathrm{~W}$ Newport 6279 NS solar simulator). The EQE spectra were collected using Oriel IQE-200 ${ }^{\mathrm{TM}}$ in air. A He discharge lamp (He I $21.22 \mathrm{eV}$ ) was applied to measure the UPS spectra. The XPS measurement (using monochromatized $\mathrm{Al} \mathrm{K \alpha}$ $\mathrm{X}$-ray photons, i.e. $h \nu=1486.6 \mathrm{eV}$, discharge lamp) was applied to measure the peaks of $\mathrm{Zn}$ and $\mathrm{O}$. The IS measurements were performed using a Zahner Zennium electrochemical workstation. The impedance spectra were recorded by utilizing an AC signal in a frequency range of $10 \mathrm{~Hz}$ to $1 \mathrm{MHz}$ with an oscillation amplitude of $10 \mathrm{mV}$. The cross-sectional SEM image of the $\mathrm{ZnO}$ film was measured using a JSM-7401F. The thicknesses of the active layers were estimated using a Surface Profilometer (Tencor, ALFA-Step 500). The thicknesses of the $\mathrm{ZnO}$ films were measured by an ellipsometer. The principle of ellipsometry is as follows: ellipsometry is an optical technique for investigating the dielectric properties (complex refractive index or dielectric function) of thin films. Ellipsometry measures the change of the polarization upon reflection or transmission and compares it to a model. The measured signal is the change in polarization as the incident radiation interacts with the material structure of interest. The polarization change is quantified by the amplitude ratio $(\Psi)$ and the phase difference $(\Delta)$. Upon the analysis of the change of the polarization of light, ellipsometry can yield information about layers that are thinner than the wavelength of the probing light itself, even down to a single atomic layer. Therefore, it can be used to characterize the thickness of the ultra-thin film, and it is very sensitive to the thickness of the material being investigated. In our experiment, the $\mathrm{ZnO}$ film is ultra-thin, so we use the Cauchy dispersion equation, which is a suitable model for fitting the data of the transparent thin film, to fit the data collected by the ellipsometer. The Cauchy dispersion equation is shown here: $n(\lambda)=A+\frac{B}{\lambda^{2}}+\frac{C}{\lambda^{4}}$. The A parameter relates to the approximate amplitude for the material index, while the $\mathrm{B}$ and $\mathrm{C}$ parameters provide the shape or curvature of the index versus the wavelength.

\section{Acknowledgements}

This work was mostly supported by the National Basic Research Program of China (Grant No. 2014CB643503), National Natural Science Foundation of China (Contract No. 61504134, 21503209), Beijing Natural Science Foundation (2162042), the Open Project Program of Surface Physics Laboratory (National Key Laboratory) of Fudan University (no. KF2015_02), the Open Project Program of National Laboratory for Infrared Physics, Chinese Academy of Sciences (no. M201503), the Open Project Program of Key Laboratory of Semiconductor Materials Science, Institute of Semiconductors (Chinese Academy of Sciences), Zhejiang Provincial Science and Technology Key Innovation Team (no. 2011R50012), and Zhejiang Provincial Key Laboratory (No. 2013E10022). Z. Wang appreciates the support from the Hundred-Talent Program (Chinese Academy of Sciences).

\section{Notes and references}

1 Z. A. Page, Y. Liu, V. V. Duzhko, T. P. Russell and T. Emrick, Science, 2014, 346, 441. 
2 Z. Qi, F. Zhang, C.-a. Di, J. Wang and D. Zhu, J. Mater. Chem. C, 2013, 1, 3072.

3 H. Shen, W. Cao, N. T. Shewmon, C. Yang, L. S. Li and J. Xue, Nano Lett., 2015, 15, 1211.

4 P. Qin, S. Paek, M. I. Dar, N. Pellet, J. Ko, M. Gratzel and M. K. Nazeeruddin, J. Am. Chem. Soc., 2014, 136, 8516.

5 N. Benaziez, A. Ounissi and S. Benaziez, J. Semicond., 2016, 37, 064004.

6 Y.-W. Su, S.-C. Lan and K.-H. Wei, Mater. Today, 2012, 15, 554-562.

7 X. Dai, C. Shi, Y. Zhang and N. Wu, J. Semicond., 2015, 36, 074003.

8 D. Chi, S. Lu, R. Xu, K. Liu, D. Cao, L. Wen, Y. Mi, Z. Wang, Y. Lei, S. Qu and Z. Wang, Nanoscale, 2015, 7, 15251.

9 H. B. Yang, Y. Q. Dong, X. Wang, S. Y. Khoo and B. Liu, ACS Appl. Mater. Interfaces, 2014, 6, 1092.

10 J. Huang, Z. Yin and Q. Zheng, Energy Environ. Sci., 2011, 4, 3861.

11 Y. Sun, J. H. Seo, C. J. Takacs, J. Seifter and A. J. Heeger, Adv. Mater., 2011, 23, 1679.

12 K. D. Kim, D. C. Lim, J. Hu, J. D. Kwon, M. G. Jeong, H. O. Seo, J. Y. Lee, K. Y. Jang, J. H. Lim, K. H. Lee, Y. Jeong, Y. D. Kim and S. Cho, ACS Appl. Mater. Interfaces, 2013, 5, 8718.

13 S. R. Cowan, P. Schulz, A. J. Giordano, A. Garcia, B. A. MacLeod, S. R. Marder, A. Kahn, D. S. Ginley, E. L. Ratcliff and D. C. Olson, Adv. Funct. Mater., 2014, 24, 4671.

14 W. Qiu, M. Buffiére, G. Brammertz, U. W. Paetzold, L. Froyen, P. Heremans and D. Cheyns, Org. Electron., 2015, 26, 30 .

15 J. Jean, S. Chang, P. R. Brown, J. J. Cheng, P. H. Rekemeyer, M. G. Bawendi, S. Gradecak and V. Bulovic, Adv. Mater., 2013, 25, 2790-2796.

16 S. Shoaee, J. Briscoe, J. R. Durrant and S. Dunn, Adv. Mater., 2014, 26, 263-268.

17 P. Zhong, W. Que, Y. N. Liang, X. Yin, Y. Liao, L. B. Kong and X. Hu, RSC Adv., 2013, 3, 17904-17913.

18 S. Alem, J. Lu, R. Movileanu, T. Kololuoma, A. Dadvand and Y. Tao, Org. Electron., 2014, 15, 1035-1042.

19 H. C. Chen, S. W. Lin, J. M. Jiang, Y. W. Su and K. H. Wei, ACS Appl. Mater. Interfaces, 2015, 7, 6273-6281.

20 Z. Jin, L. Gao, Q. Zhou and J. Wang, Sci. Rep., 2014, 4, 4268.

21 X. Xu, Q. Cui, Y. Jin and X. Guo, Appl. Phys. Lett., 2012, 101, 222114.
22 Y. H. Lin, H. Faber, K. Zhao, Q. Wang, A. Amassian, M. McLachlan and T. D. Anthopoulos, Adv. Mater., 2013, 25, 4340.

23 C.-s. Li, Y.-n. Li, Y.-l. Wu, B.-S. Ong and R.-O. Loutfy, J. Mater. Chem., 2009, 19, 1626.

24 H. Hoppe and N. S. Sariciftci, Adv. Polym. Sci., 2008, 214, 1.

25 H. Hoppe and N. S. Sariciftci, J. Mater. Res., 2004, 19, 1924.

26 B. C. Thompson and J. M. Frechet, Angew. Chem., Int. Ed.

Engl., 2008, 47, 58.

27 G. Dennler, M. C. Scharber and C. J. Brabec, Adv. Mater., 2009, 21, 1323.

28 D. Chi, C. Liu, S. Qu, Z.-G. Zhang, Y. Li, Y. Li, J. Wang and Z. Wang, Synth. Met., 2013, 181, 117.

29 B. Qi and J. Wang, J. Mater. Chem., 2012, 22, 24315.

30 K. Vandewal, K. Tvingstedt, A. Gadisa, O. Inganäs and J. V. Manca, Nat. Mater., 2009, 8, 904.

31 W. J. Potscavage, S. Yoo and B. Kippelen, Appl. Phys. Lett., 2008, 93, 193308.

32 B. Qi and J. Wang, Phys. Chem. Chem. Phys., 2013, 15, 8972.

33 D. Chi, S. Qu, Z. Wang and J. Wang, J. Mater. Chem. C, 2014, 2, 4383.

34 V. Mihailetchi, L. Koster, J. Hummelen and P. Blom, Phys. Rev. Lett., 2004, 93, 216601.

35 V. D. Mihailetchi, H. X. Xie, B. de Boer, L. J. A. Koster and P. W. M. Blom, Adv. Funct. Mater., 2006, 16, 699.

36 F. Tan, S. Qu, Q. Jiang, J. Liu, Z. Wang, F. Li, G. Yue, S. Li, C. Chen, W. Zhang and Z. Wang, Adv. Energy Mater., 2014, 4, 1400512.

37 F. Tan, Z. Wang, S. Qu, D. Cao, K. Liu, Q. Jiang, Y. Yang, S. Pang, W. Zhang, Y. Lei and Z. Wang, Nanoscale, 2016, 8, 10198.

38 A. Manjceevan and J. Bandara, Sol. Energy Mater. Sol. Cells, 2016, 147, 157.

39 U. Rau, P. O. Grabitz and J. H. Werner, Appl. Phys. Lett., 2004, 85, 6010.

40 M. S. Kim, B. G. Kim and J. Kim, ACS Appl. Mater. Interfaces, 2009, 1, 1264.

41 J. Xue, S. Uchida, B. P. Rand and S. R. Forrest, Appl. Phys. Lett., 2004, 84, 3013.

42 J. D. Servaites, S. Yeganeh, T. J. Marks and M. A. Ratner, Adv. Funct. Mater., 2010, 20, 97.

43 B. Muhsin, J. Renz, K.-H. Drue, G. Gobsch and H. Hoppe, Phys. Status Solidi A, 2009, 206, 2771.

44 B. J. Leever, C. A. Bailey, T. J. Marks, M. C. Hersam and M. F. Durstock, Adv. Energy Mater., 2012, 2, 120.

45 J. Bisquert, J. Phys. Chem. B, 2002, 106, 325.

46 B. Qi, Z. G. Zhang and J. Wang, Sci. Rep., 2015, 5, 7803. 